\title{
Correction to: Long noncoding NONRATT021972 siRNA normalized abnormal sympathetic activity mediated by the upregulation of P2X7 receptor in superior cervical ganglia after myocardial ischemia
}


Zhihua $\mathrm{Yi}^{1} \cdot \mathrm{Xi}_{\text {Zhang }}{ }^{1} \cdot$ Guilin Li $^{1}$. Shangdong Liang ${ }^{1,2}$

Accepted: 15 September 2020 / Published online: 3 October 2020

(C) Springer Nature B.V. 2020

Correction to: Purinergic Signalling (2016) 12:521-535

https://doi.org/10.1007/s11302-016-9518-3

Due to the authors' carelessness, we used mistakenly images in Fig. 5B(B1) for P2X7 immunoreactivity in Control, Sham, $\mathrm{MI}, \mathrm{MI}+\mathrm{BBG}, \mathrm{MI}+\mathrm{SC}$ si, $\mathrm{MI}+\mathrm{P} 2 \mathrm{X} 7$ si and Blank groups. Original Fig. 5B(B1)


MI+SC si $\quad$ MI+NONRATT021972 si $\quad$ MI+P2X ${ }_{7}$ si

\section{Blank}


Guihua Tu, Lifang Zou, and Shuangmei Liu are Joint first authors.

The online version of the original article can be found at https:/doi.org/ 10.1007/s11302-016-9518-3

Guilin Li

li.guilin@163.com

Shangdong Liang

liangsd@hotmail.com

1 Department of Physiology, Medical College of Nanchang University, Nanchang 330006, People's Republic of China

2 Institute of Life Science of Nanchang University, Nanchang 330006 , People's Republic of China 
The photos of P2X7 immunoreactivity in Control, Sham, MI, $\mathrm{MI}+\mathrm{BBG}, \mathrm{MI}+\mathrm{SC}$ si, MI+P2X7 si and blank groups were replaced.

Corrected 5B(B1)
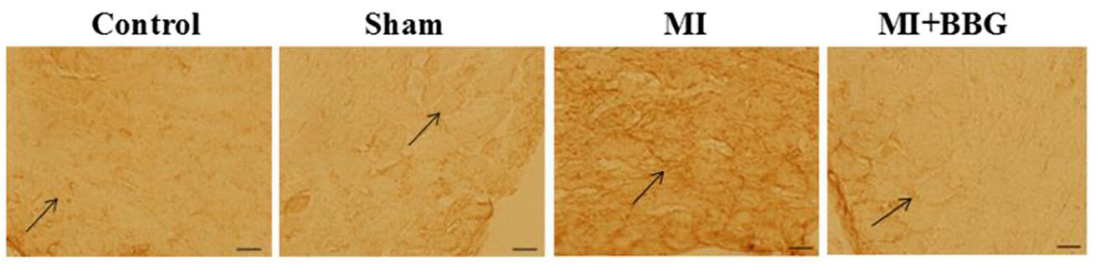

MI+SC si $\quad$ MI+NONRATT021972 si $\quad M I+P_{2} X_{7}$ si

Blank
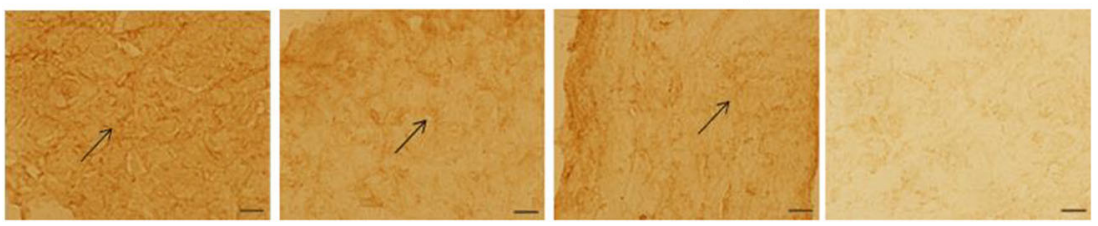

Publisher's note Springer Nature remains neutral with regard to jurisdictional claims in published maps and institutional affiliations. 